Fifth International Conference on Sustainable Construction Materials and Technologies. http://www.claisse.info/Proceedings.htm

\title{
ULTRA HIGH PERFORMANCE FIBER REINFORCED CONCRETE AS STRENGTHENING MATERIAL
}

\author{
Dr Spyridon A. Paschalis, PhD \\ Lecturer in Civil Engineering, School Of Engineering, University of Bolton \\ Email: s.paschalis@bolton.ac.uk, s.paschalis493@gmail.com,
}

Tel: +44 (0) 7522129300

\begin{abstract}
The safety of structures is of high importance affecting people's lives. Structural evaluation, and possibly intervention, is considered necessary for old structures, structures which have been affected by accidental actions and also for structures in high seismic risk areas. Research should now focus on the development of new sustainable techniques which increase the safety of existing structures, and at the same time minimize the necessary to build new structures and to consume new materials and resources. The present research investigates the effectiveness of an advanced material, such as Ultra High Performance Fiber Reinforced Concrete (UHPFRC), for the strengthening of existing Reinforced Concrete (RC) structures. For this reason, an extensive experimental study on the properties of the material and the application for strengthening of RC beams has been conducted. More specifically, parameters such the effect of fiber content on the performance, the workability and the cost of the material have been investigated first. Based on the analysis, an optimum mixture design has been selected and has been applied for strengthening of RC beams using different configurations. The results indicated that the strengthening with UHPFRC is a well promising technique and the performance of the strengthened elements has been increased in all the examined cases.
\end{abstract}

Keywords: Fiber reinforced concrete, fiber content

\section{INTRODUCTION}

Most of the new Reinforced Concrete (RC) structures which are built nowadays meet the criteria for safe building design. However, we cannot claim the same for structures were built in the past. Most of these structures have been designed without any regulation, or based on codes which have been proved to be deficient. Safety of structures also concerns structures which have been affected by accidental actions, while it is also a very important issue in high seismic risk areas. Research should now focus on the development of new sustainable techniques for the strengthening of these structures, in order to increase their safety, and at the same time, to minimize the necessary to build new structures and to consume new materials and resources.

Existing techniques present crucial disadvantages which are related to parameters such as; the ease of preparation and application of the technique, the high cost, the total time which is required for the application of the technique, and also, the disturbance on the occupancy. Ultra High Performance Fiber Reinforced Concrete (UHPFRC) is a 
material which is characterized by enhanced properties in tension and compression and high energy absorption in the post-cracking state. The unique properties of UHPFRC make the application of the material attractive for strengthening applications. The present research investigates the application of UHPFRC as strengthening material. The advantages of the application of UHPFRC for strengthening purposes are related to parameters such as; the high properties of the material, the durability and the ease of preparation of the material. Also, thin elements with high strength can be constructed. Finally, another important parameter which should be taken into consideration is that UHPFRC is a cementitious material and its characteristics are not much dissimilar compared to concrete.

The properties of UHPFRC have been investigated in a number of studies. Nicolaides et al. (2015), presented an experimental work which was focused on the development of Ultra High Performance Cementitious Composites locally available in Cyprus. In this study, different parameters which affect the strength and the workability of UHPFRC have been investigated and an optimum mixture design was proposed. Paschalis and Lampropoulos (2017), investigated the tensile characteristics of UHPFRP for different curing regimes and different fiber contents. Based on the results, different stress-strain models for the different fiber contents have been proposed, while an optimum curing period for the UHPFRC has been suggested. The importance of fiber distribution on the performance of UHPFRC highlighted by Ferrara et al. (2011), while the performance of UHPFRC under cyclic loading has been investigated by Paschalis and Lampropoulos (2016).

There are only limited studies on the investigation of the performance of UHPFRP as repair and strengthening material. Habel et al. (2006), presented an analytical investigation of the performance of composite UHPFRC-concrete elements under the assumption of perfect bonding between the old and the new elements, while a numerical study which investigates the structural performance of beams strengthened with UHPFRC layers was presented by Lampropoulos et al. (2016). Paschalis et al. (2018), presented a novel investigation of the interface characteristics between UHPFRC and RC.

The present study aims to investigate the application of UHPFRC as strengthening material and to give to the scientific community and practitioners useful information for the design of the technique. The first part of the present research is focused on the investigation of parameters which should be taken into consideration for the preparation of UHPFRC. A crucial decision for the design of UHPFRC is the amount of fibers in the mixture. For this reason, the properties of the material in tension and compression have been investigated using different fiber contents, and parameters such as the workability and the cost of the material have been analysed. Based on the results, an optimum mixture has been selected and has been applied for the strengthening of full scale $\mathrm{RC}$ beam using different configurations. In the present investigation, novel parameters such as the connection between UHPFRC and RC have been investigated and a comparison with proposed values in the literature review, for concrete to concrete interfaces, is presented. Finally, the effectiveness of each configuration has been evaluated. 


\section{INVESTIGTION OF UHPFRC PROPERTIES FOR DIFFERENT FIBER CONTENTS}

An important parameter which should be taken into consideration for the preparation of the UHPFRC is amount of fibers in the mixture. Different fiber contents can have effect on the mechanical properties of the material, the workability and the cost. In the present section, the properties and the workability of UHPFRC for different fiber contents have been investigated. Additionally, a cost analysis of the material for the different fiber contents has been conducted. Based on the results of the present investigation, an optimum mixture for the preparation of UHPFRC has been selected and has been applied for the strengthening of RC beams using UHPFRC layers.

\subsection{Preparation of the Specimens}

In the present investigation 5 different fiber contents have been investigated, namely; 1 Vol.-\%, 2 Vol.-\%, 3 Vol.-\%, 4 Vol.-\%, and 6 Vol.-\%. Cube specimens, with side lengths of $100 \mathrm{~mm}$, have been used for the investigation of the compressive strength of the material and dog bone specimens have been used for the investigation of the tensile characteristics.

For the preparation of UHPFRC, silica sand with a maximum particle size of $500 \mu \mathrm{m}$ has been used together with silica fume and Ground Granulated Blast Furnace Slag (GGBS). Additionally, straight steel fibers with a length of $13 \mathrm{~mm}$, a diameter of 0.16 $\mathrm{mm}$ and a tensile strength of $3000 \mathrm{MPa}$ have been incorporated in the mixture. In Table 1 , the mixture design for the preparation of UHPFRC is presented.

Table 1 Mixture Design for UHPFRC

\begin{tabular}{|c|c|c|c|c|c|}
\hline Material & \multicolumn{5}{|c|}{$\begin{array}{l}\text { Mixture proportions } \\
\qquad\left(\mathrm{kg} / \mathbf{m}^{3}\right)\end{array}$} \\
\hline Cement & \multicolumn{5}{|c|}{620} \\
\hline GGBS & \multicolumn{5}{|c|}{434} \\
\hline Silica fume & \multicolumn{5}{|c|}{140} \\
\hline Silica Sand & \multicolumn{5}{|c|}{1051} \\
\hline Superplasticizer & \multicolumn{5}{|c|}{59} \\
\hline Water & \multicolumn{5}{|c|}{185} \\
\hline Mixture & U1 & $\mathrm{U} 2$ & U3 & U4 & U6 \\
\hline Steel fibers & $\begin{array}{c}78.5 \\
(1 \mathrm{Vol.-} \%)\end{array}$ & $\begin{array}{c}157 \\
(2 \mathrm{Vol.-} \%)\end{array}$ & $\begin{array}{c}235.5 \\
(3 \text { Vol.-\%) }\end{array}$ & $\begin{array}{c}314 \\
(4 \text { Vol.-\%) }\end{array}$ & $\begin{array}{c}471 \\
(6 \text { Vol.-\%) }\end{array}$ \\
\hline
\end{tabular}




\subsection{Testing of the Specimens and Experimental Results}

For the investigation of the tensile characteristics of UHPFRC, and for each fiber content, six identical dog bone specimens have been tested under a constant displacement rate of $7 \mu \mathrm{m} / \mathrm{s}$. The experimental setup for these tests is presented in Figure 1a. As can be seen, the specimens failed due a single crack in the middle of the length of the specimens. The compressive tests on the other hand were conducted under a constant loading rate of $0.6 \mathrm{MPa} / \mathrm{s}$, according to BS EN 12390-3:2009 (2009) (Figure 1b).
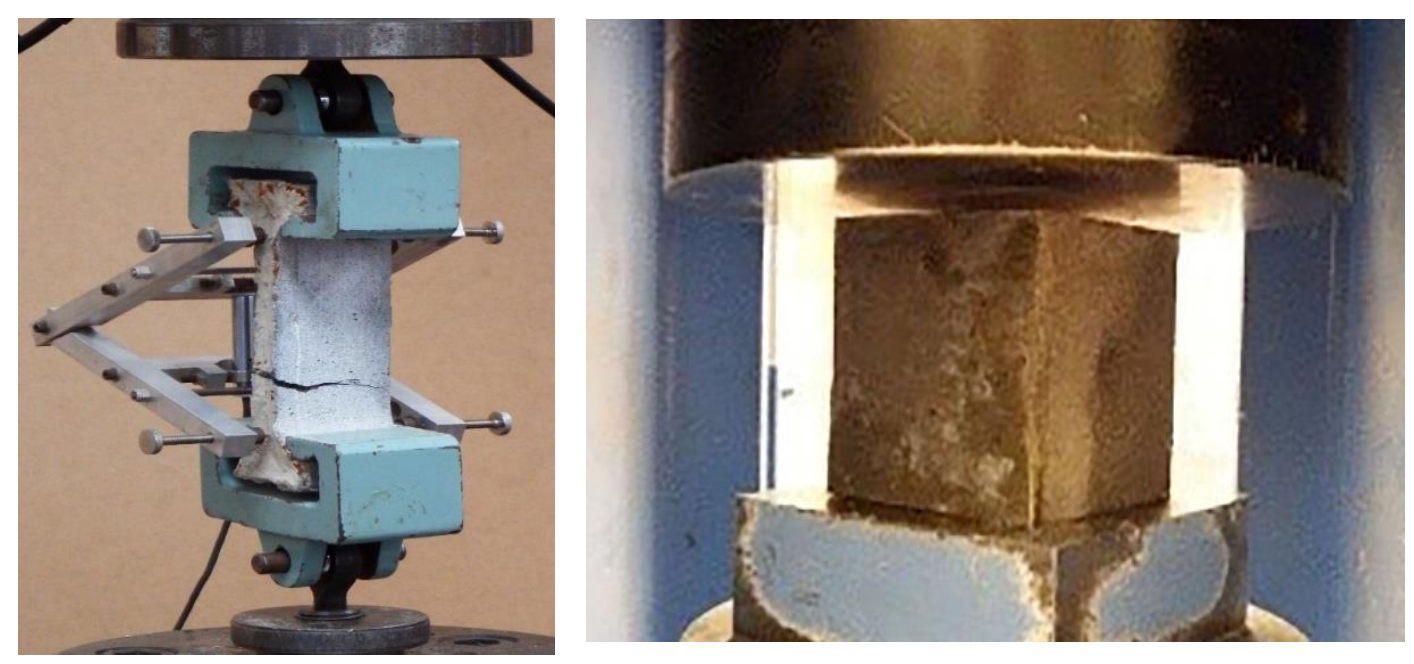

Figure 1 a) Dog Bone specimen b) Cube specimen

In Figure 2, the average tensile stress-strain curves, for the different fiber contents are presented.

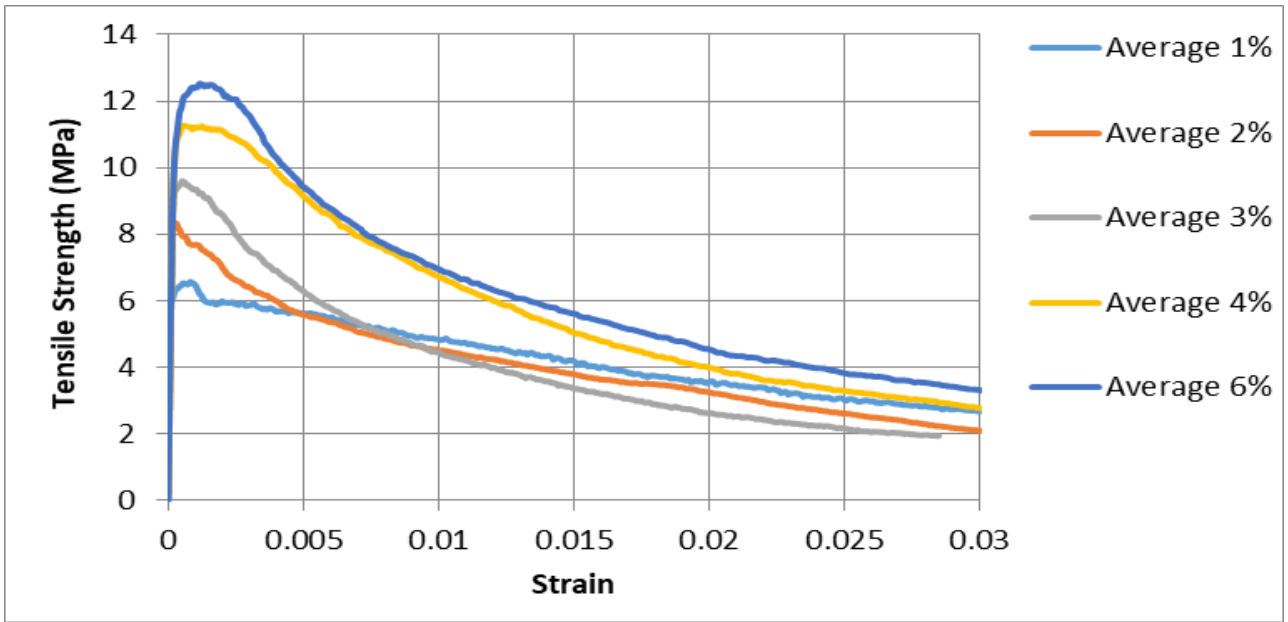

Figure 2 Stress-strain results in tension for the different fiber contents 
In Table 2, the values for the maximum tensile strength and compressive strength are presented.

Table 2. Maximum tensile and compressive strengths

\begin{tabular}{ccc}
\hline Fiber Content (\%) & $\begin{array}{c}\text { Tensile Strength } \\
\text { (MPa) }\end{array}$ & $\begin{array}{c}\text { Compressive } \\
\text { Strength (MPa) }\end{array}$ \\
\hline 1 & 6.5 & 102 \\
2 & 8.4 & 115.6 \\
3 & 9.6 & 125.6 \\
4 & 11.3 & 136.1 \\
6 & 12.5 & 175.5 \\
\hline
\end{tabular}

The results of Figure 2 indicate that the fiber content is a crucial parameter affecting the tensile characteristics of UHPFRC. It has been identified that strain hardening is achieved for fiber content higher than 2 Vol.- $\%$. From Table 2, it can be noticed that when the fiber content is increased from 1 to $6 \mathrm{Vol} .-\%$, the tensile strength is increased by $92 \%$ and the compressive strength by $73.4 \%$.

During the preparation of the specimens it was noticed that for increasing fiber contents the workability was reduced. This was confirmed with the measurement of the workability, following the procedure proposed by BS 1015-3:1999 (1999). More specifically, the workability of the specimens without fibers, as well as with 3 Vol.-\% and 6 Vol.- $\%$ steel fibers was measured using a flow table. The applied cone had a height of $60 \mathrm{~mm}$, a top diameter of $70 \mathrm{~mm}$ and a bottom diameter of $100 \mathrm{~mm}$.

The result indicated that the flow diameter of UHPC, without fibers, was $255 \mathrm{~mm}$ and the respective values for the mixtures with 3 Vol.- $\%$ and 6 Vol.- $\%$ steel fibers were equal to $215 \mathrm{~mm}$ and $125 \mathrm{~mm}$, respectively. These results indicate a good workability for the mixture without fibers, as well as for the mixture with $3 \mathrm{Vol} .-\%$. On the contrary, the high volume of steel fibers in the mixture prepared with 6 Vol.- $\%$ caused a pronounced reduction in flow. For the application of UHPFRC for strengthening of RC structures, good rheological properties are required. From the measurements of the workability it is obvious that the incorporation of high volumes of fiber, such as 6 Vol.$\%$, have negative effect on the workability of the material and may cause problems to the application of the material.

Another important parameter which should be taken into consideration for the preparation of the UHPFRC is the cost. Higher fiber contents increase the cost of the material. In Table 3, an estimation of the cost of UHPFRC for the different fiber contents is presented. 
Table 3. Cost of UHPFRC for different fiber contents

\begin{tabular}{cc}
\hline Fiber Content (Vol. \%) & Cost (£/m3) \\
\hline 1 & 1212 \\
2 & 1542 \\
3 & 1872 \\
4 & 2201 \\
6 & 2861 \\
\hline
\end{tabular}

From the results of Table 3, an almost linear increment of the cost for increasing fiber contents can be distinguished. When the fiber content is increased from 1 to 6 Vol.-\% an increment of $136 \%$ on the total cost can be observed.

Taking into consideration parameters such as the properties of the material, the cost, the workability and the ease of preparation and application of the material, a fiber content between $3-4 \%$ is considered ideal. However, it should be noted that the decision for the selection of the optimum fiber content should be depended on the expected outcomes and structural requirements of the application.

\section{STRENGTHENEING OF RC BEAMS USING UHPFRC}

\subsection{Preparation and Testing of the Specimens}

In the present section, the effectiveness of UHPFRC as a strengthening material is investigated. UHPFRC has been cast as thin layers for the strengthening of RC beams, and the performance of the strengthened elements has been evaluated. For this investigation, six identical RC beams were constructed. Two beams were used as control beams, two beam were strengthened with UHPFRC layers and two beam were strengthened with UHPFRC layers and steel bars (Table 4). Following the results and the conclusions of the previous section, a fiber content of $3 \mathrm{Vol} \%$ has been selected for the preparation of UHPFRC. The mixture design for the preparation of RC beams is presented in Table 5 . 
Table 4. Examined beams

\begin{tabular}{cc}
\hline Beam & $\begin{array}{c}\text { Strengthening } \\
\text { Technique }\end{array}$ \\
\hline P1 & Control beam \\
P2 & Control beam \\
U1 & UHPFRC layer \\
U2 & $\begin{array}{c}\text { UHPFRC layer } \\
\text { UHPFRC layer } \\
\text { and bars } \\
\text { UB1 }\end{array}$ \\
UB2 & $\begin{array}{c}\text { UHPFC layer } \\
\text { and bars }\end{array}$ \\
\hline
\end{tabular}

Table 5. The concrete mix design

\begin{tabular}{cc}
\hline Material & Quantity $\left(\mathrm{kg} / \mathrm{m}^{3}\right)$ \\
\hline Cement & 340 \\
Fine Aggregates & 1071 \\
Coarse & 714 \\
Aggregates & \\
Water & 205
\end{tabular}

The geometry and the reinforcement of the initial RC beams are presented in Figure 3. As can be seen in this figure, the existing $\mathrm{RC}$ beams were reinforced at the tensile side with two longitudinal ribbed steel bars with a diameter of $12 \mathrm{~mm}$ and a length of 2150 $\mathrm{mm}$. The reinforcement at the compressive side of beams was used to support the stirrups. In order to avoid shear failure of the beams, shear reinforcement, according to Eurocode 2 (2004) was selected. The UHPFRC layers had a depth of $50 \mathrm{~mm}$, a breadth of $150 \mathrm{~mm}$ and were cast along the whole length of the tensile side of the beams. Two ribbed steel bars with a diameter of $10 \mathrm{~mm}$, a length of $2150 \mathrm{~mm}$ and a cover of $25 \mathrm{~mm}$ were used as a reinforcement of the UHPFRC layers. All the steel bars of the present investigation were grade B 500C. Before the casting of the layers, the interface was roughened to a depth of 2-2.5 mm, which according to fib bulletin 55 (2010), can be classified as rough interface. The roughness depth was measured using the sand patch method.

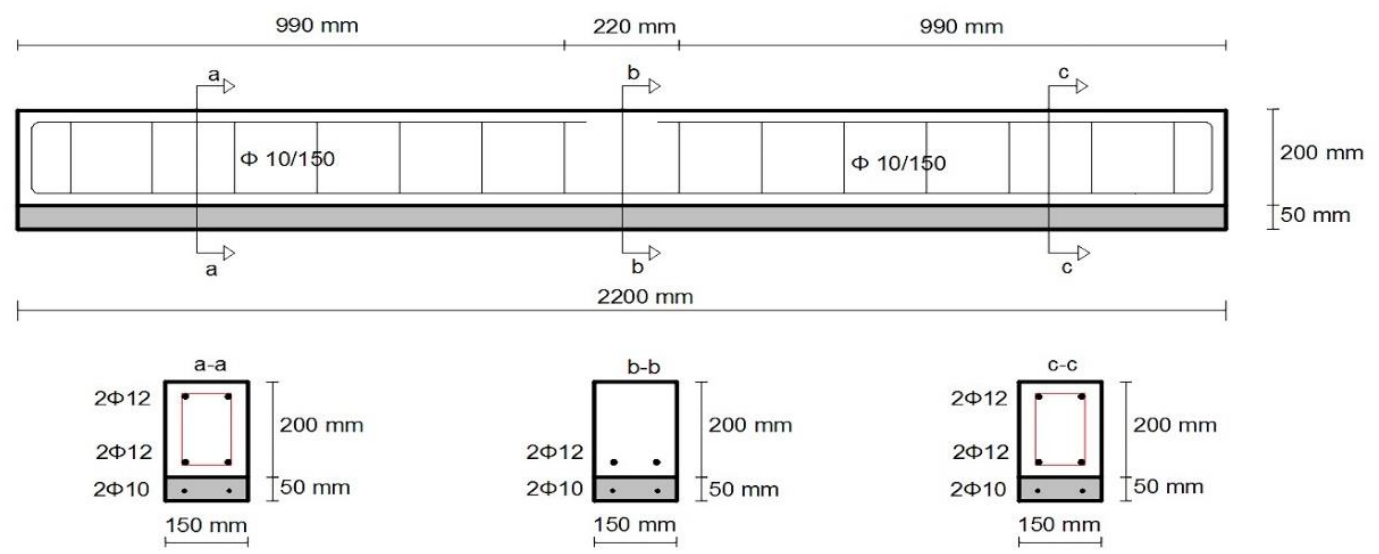

Figure 3. Geometry and Reinforcement of the examined beams 
The examined beams, were tested under a constant displacement rate of $8 \mu \mathrm{m} / \mathrm{s}$. The experimental setup for these tests is presented in Figure 4.

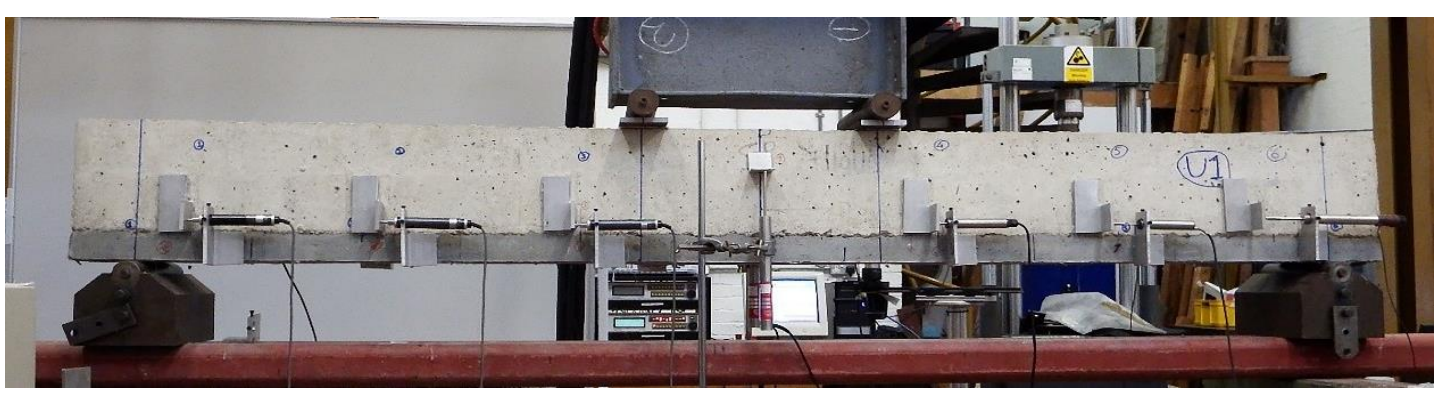

Figure 4. Experimental setup for the four point loading tests

As shown in Figure 4, during the testing, the deflection of the specimens in the middle of the span length and both sides was recorded. The deflection was measured using Linear Variable Differential Transformers (LVDTs). Additionally, for the beams which were strengthened with layers, the slips at the interface were also recorded using nine LVDTs in total. The position of the LVDTs is presented in Figures $5 \mathrm{a}$ and $5 \mathrm{~b}$.

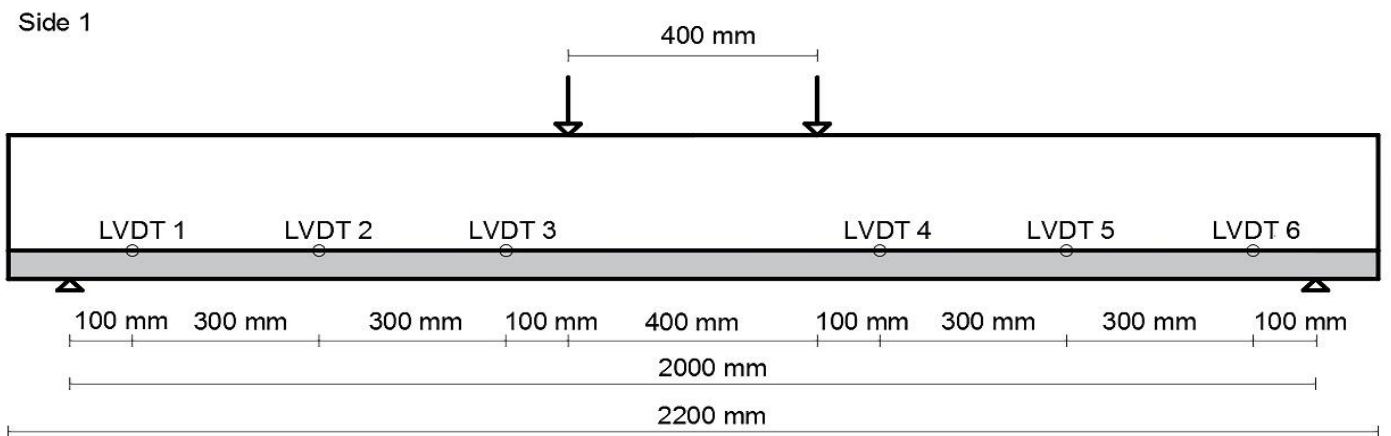

a)

Side 2

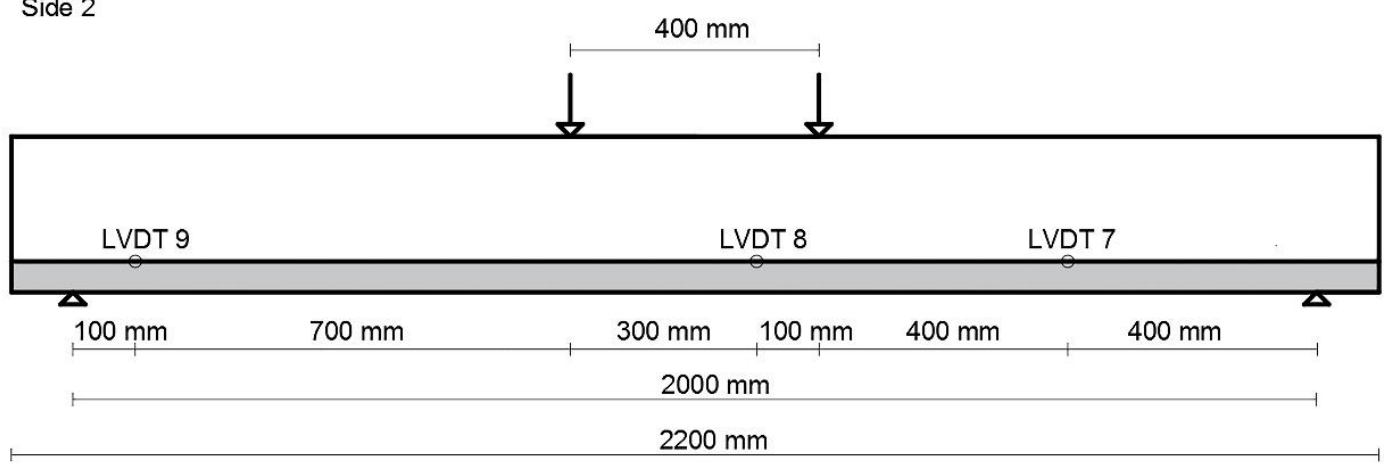

b)

Figure 5 a) Positions of the LVDTs for the measurement of slips on side $1 \mathrm{~b}$ ) positions of the LVDTs for the measurement of slips on side 2 


\subsection{Experimental Results}

From the testing of three concrete cubes with side lengths of $100 \mathrm{~mm}$, and following the procedure as described in section 2.2, it was found that the average compressive strength of concrete was equal to $30.9 \mathrm{MPa}$ and the standard deviation was $2.34 \mathrm{MPa}$. All the experimental results from the testing of the RC beams and the strengthened beams are presented in Figure 6.

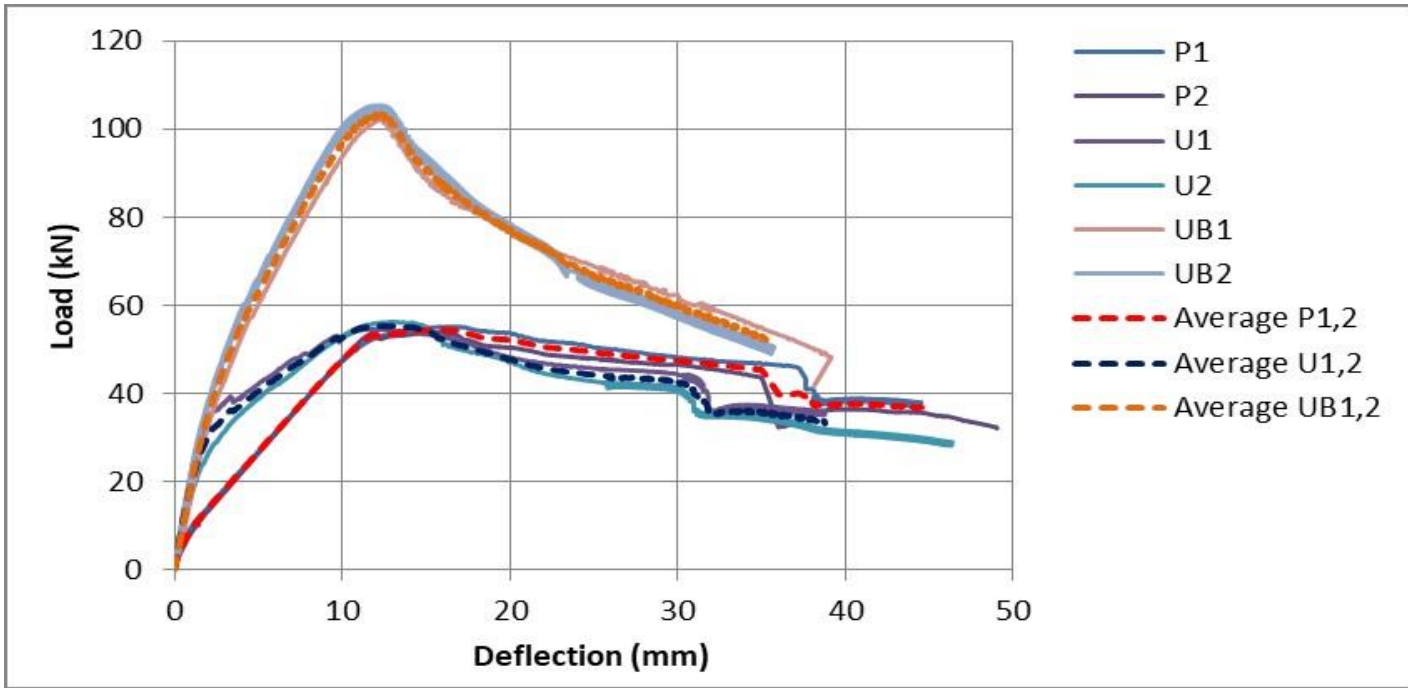

Figure 6. Load-deflection results for all the examined beams

From the results of Figure 6, it is clear that the addition of UHPFRC layers at the tensile side of the RC beams resulted in a large increase of the stiffness of the RC beams, while the load carrying capacity was also increased. The addition of steel bars to the UHPFRC layer on the other hand, had as a result a big increase of the load carrying capacity of the beams. From the comparison of the average curves, it can be noticed that the addition of steel bars to the layers had as a result $90 \%$ higher load carrying capacity compared to the load carrying capacity of the control beams.

The failure mode of the initial beams prior to strengthening, as well as of the strengthened beams with UHPFRC layers only was identical. A single crack in the middle of the span length, and at the tensile side of the beams, was crucial for the failure of the beams. On the contrary, the damage of the beams which were strengthened with UHPFRC layers and steel bars, started from the compressive side and progressively propagated at the tensile side. In Figure 7, the failure mode of the strengthened beams for the different configurations is presented. 


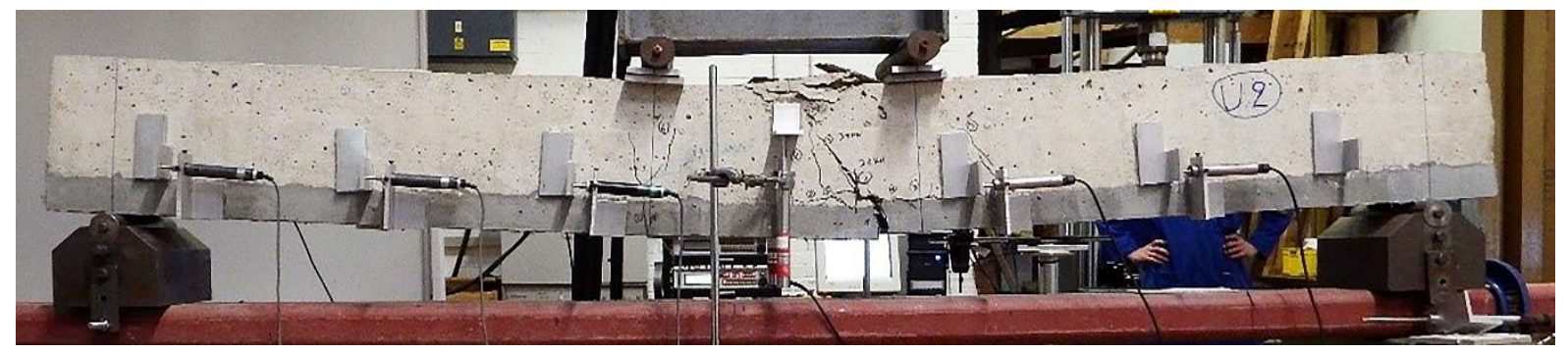

a)

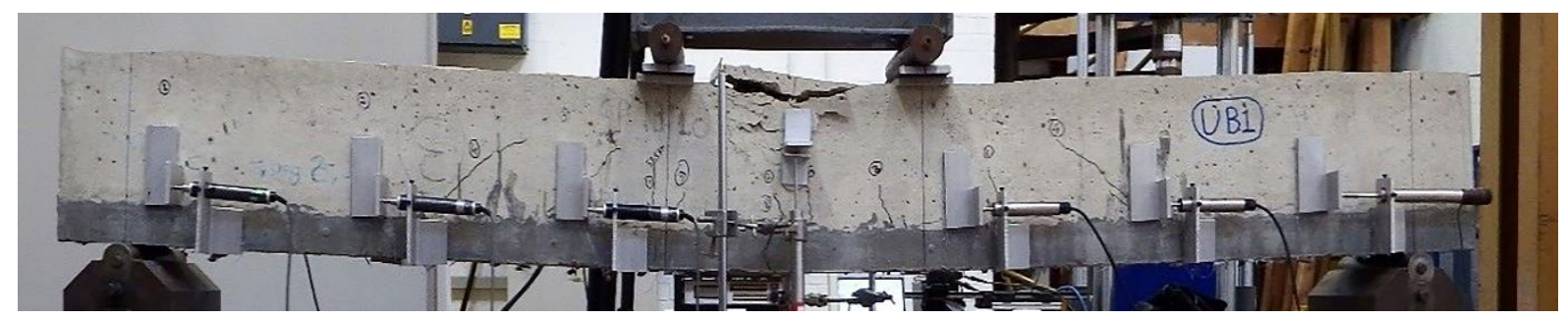

b)

Figure 7. Failure mode of a) beam strengthened with UHPFRC layer b) beam strengthened with UHPFRC layer and steel bars

During the testing of the strengthened beams, the slips at the interface in different positions were also recorded (see Figures $5 \mathrm{a}$ and $5 \mathrm{~b}$ ). Due to the local de-bonding at the interface of beam U1, the measurements for this beams were ignored. The results for the load versus the slip for beams U2, UB1 and UB2 are presented in Figures 8a-c.

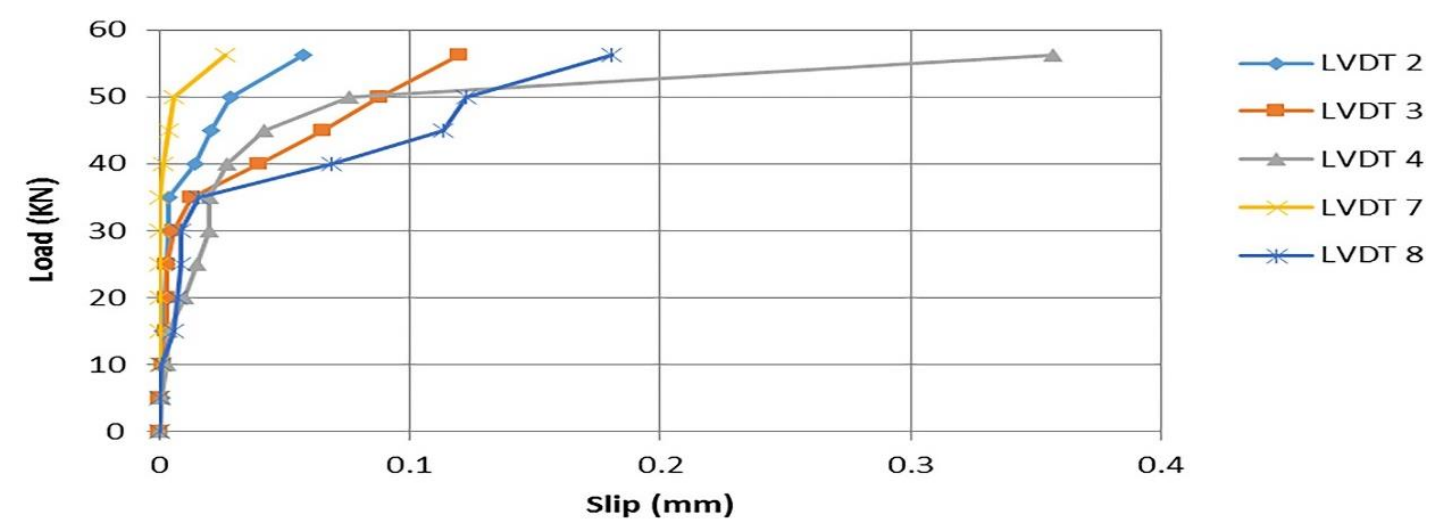

a) 


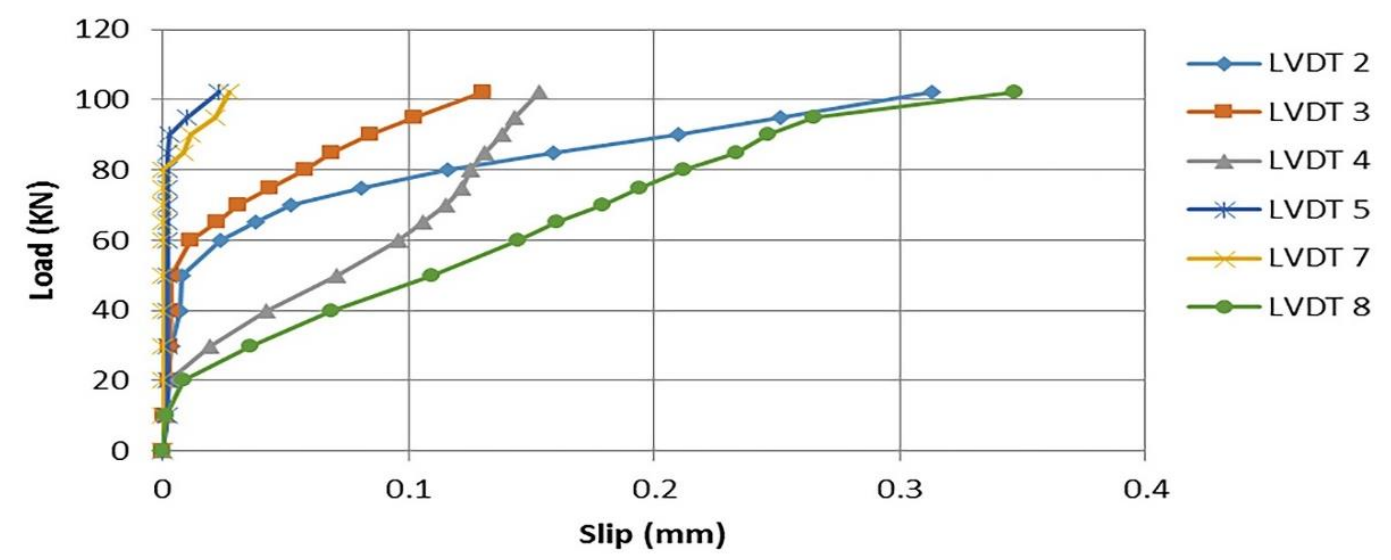

b)

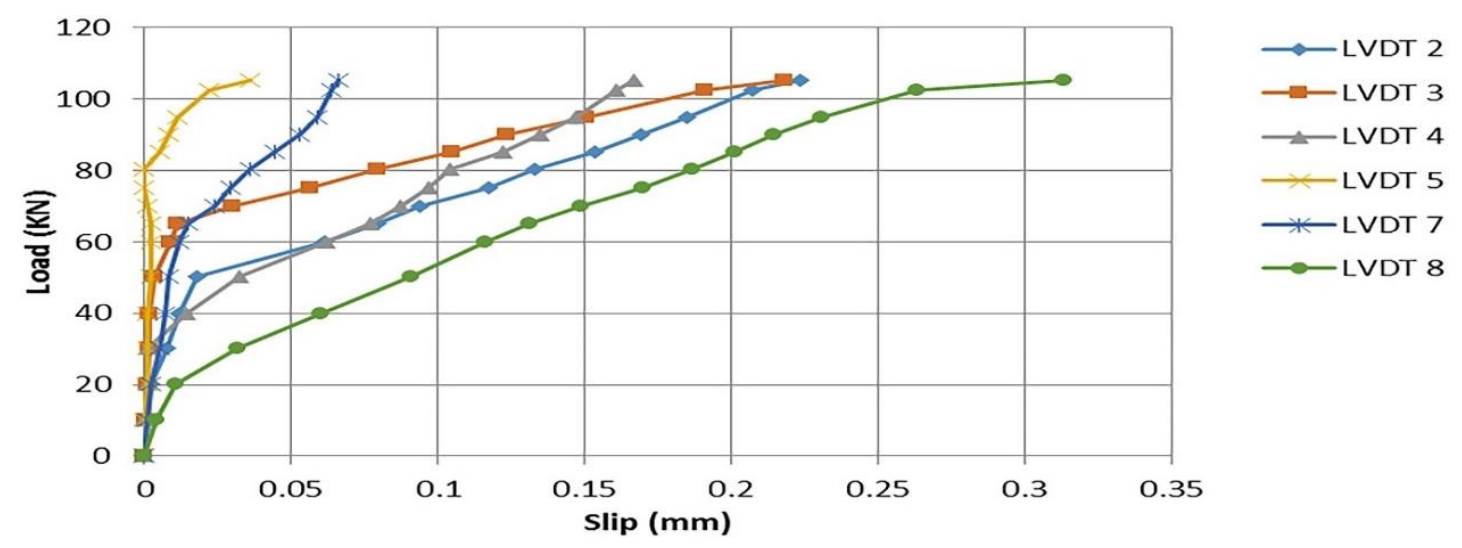

c)

Figure 8. load versus slip in different positions for a) beam U2 b) beam UB1 c) beam UB2

From the results of Figures 8a-c, it is clear that there are differences in the values of slips in different positions. The slips close to supports were almost zero. In case of high normal to the interface stress, like areas close to supports, the shear strength is higher than the shear stress and therefore interface slip is prevented. Also, it should be noted that despite the fact that in the present study the sand patch method was used to quantify the concrete surface texture, it is possible that there were local imperfections and variations of the level of preparation along the interface.

In existing codes, limit state values for the design of composite structures, are proposed. The Greek Code of Interventions (2013) suggests maximum values of slips for different limit states of composite elements. More specifically, a value of $0.2 \mathrm{~mm}$ is proposed for the immediate occupancy performance level, a value of $0.8 \mathrm{~mm}$ for the life safety performance level and a value of $1.5 \mathrm{~mm}$ for the collapse prevention performance level. In all the examined cases the recorded values of the present investigation were lower to $0.35 \mathrm{~mm}$ which according this code corresponds to the life safety performance level.

Comparing the obtained values, with proposed values in the literature for concrete to concrete interfaces, a better bonding between UHPFRC and RC can be identified. 
Tsioulou et al. (2013), recorded values of slip equal to $1.1 \mathrm{~mm}$ at the interface between RC beams and RC layers. This value corresponds to the collapse prevention performance level and it is significantly higher compared to the recorded values of the present study. The loading conditions, the loading rate and the dimensions of the specimens of this study were identical with the present study. Therefore, the results are comparable.

\section{CONCLUSIONS}

In the present study the effectiveness of UHPFRC as a strengthening material has been investigated. From the results of the present investigation the following conclusions can be drawn:

1. The incorporation of higher fiber contents in the mixture of UHPFRC has as a result higher tensile and compressive strength. Strain hardening is achieved for fiber contents higher than 2 Vol.- $\%$.

2. The addition of high volumes of fibers in the UHPFRC mixture has as a result a linear increase of the cost and a pronounced reduction in the flow of the material. More specifically, for fiber contents higher than 4 Vol.- $\%$ there is a difficulty on the preparation and application of the material. Therefore, for applications where good rheological properties are required, fiber contents higher than 4 Vol.-\% are not suggested.

3. Considering parameters such as the performance, the cost and the ease of preparation and application of the material, a fiber content between 3-4 Vol.-\% is considered ideal for the preparation of the material. However, it should be noted that the selection of the appropriate fiber content is dependent on the expected outcomes and the structural requirements of the application.

4. The addition of UHPFRC layers for the strengthening of existing RC beams can produce a big increase of the stiffness of the existing members and the formation of cracks can be delayed.

5. The addition of steel bars to the layers can increase the load carrying capacity of the strengthened elements dramatically.

6. The bonding between UHPFRC and concrete is effective, with low values of slips at the interface, and its is better compared to concrete to concrete interfaces.

UHPFRC is a material with enhanced properties and the results of the present study confirm that the application of UHPFRC for the strengthening of existing RC beams is a well promising technique. An important finding of the present study, which has not been investigated to date, is that the bonding between UHPFRC and concrete is effective with low values of slip at the interface. On the contrary, based on existing studies in the literature, the connection between concrete to concrete interfaces is not effective, which means that the use of steel connectors at the interface is considered necessary. Finally, another important finding of the present study, which should be taken into consideration for the design of the examined technique, is that despite the 
fact that higher fiber contents result in better mechanical properties, as expected, from practical point of view, the addition of high volumes of fibers may result in difficulties in the preparation and application of the material, and therefore is not suggested.

\section{ACKNOWLEDGEMENTS}

The author would like to express his sincere gratitude to Dr Andreas Lampropoulos for his guidance during the present research.

\section{REFERENCES}

BS EN 12390-3:2009, (2009).Testing hardened concrete-Part 3: Compressive strength of test specimens.

BS EN 1015-3:1999 (1999). Methods of test for mortar for masonry-Part 3: Determination of consistence of fresh mortar (by flow table).

Eurocode 2, CEN En 1992-1-1, (2004). Eurocode 2: Design of concrete structures Part 1-1: General rules and rules for buildings. Brussels: European Committee for Standardization; 2004

Ferrara L, Ozyurt N, Di Prisco M., (2011). High mechanical performance of fiber reinforced cementitious composites: the role of "casting-flow induced" fiber orientation, Materials and Structures, 44 (1), 109-128.

fib Bulletin No 55. Model Code 2010, (2010).. Lausanne: International Federation for Structural Concrete (fib)

Greek Retrofitting Code, (GRECO), (2013). Greek Organization for Seismic Planning and Protection, Athens, Greek Ministry for Environmental Planning and Public Works, (in Greek)

Habel K., Denarie E., Bruhwiler E., (2006). Structural response of elements combining Ultra- High-Performance Fiber Reinforced Concretes and Reinforced Concrete (2006). Journal of Structural Engineering, 132 (11): (2006), 1793-1800.

Lampropoulos, A., Paschalis, S.A., Tsioulou O., Dritsos S. (2015), "Strengthening of reinforced concrete beams using ultra high performance fibers reinforced concrete (UHPFRC)” Engineering Structures, 106, 370-384.

Nicolaides D., Kanellopoulos A., Petrou M., Savva P., Mina A., (2015). Development of a new Ultra High Performance Fiber Reinforced Cementitious Composite (UHPFRCC) for impact and blast protection of structures, Construction and Building Materials, 95, 667-674.

Paschalis, S.A., Lampropoulos A. (2016), "Ultra High Performance Fiber Reinforced Concrete Under Cyclic Loading” ACI Materials Journal, 113 (4), 419-427.

Paschalis, S.A., Lampropoulos, A. (2017), "Fiber content and curing time effect on the tensile characteristics of Ultra High Performance Fiber Reinforced Concrete 
(UHPFRC)", $\quad$ Structural $\quad$ Concrete, $18 \quad$ (4), 577-588, https://doi.org/10.1002/suco.201600075

Paschalis, S.A., Lampropoulos, A., Tsioulou, O., (2018), "Experimental and numerical study of the performance of Ultra High Performance Fiber Reinforced ConcreteReinforced Concrete for the flexural strengthening of full scale members", Construction and building materials, 186, 351-366

Tsioulou, O., Lampropoulos, A., Dritsos, S., (2013). Experimental investigation of interface behavior of RC beams strengthened with concrete layers, Construction and Building Materials, 40, 50-59. 